\title{
Promoção da higienização das mãos: relato de experiência
}

\author{
Hand hygiene promotion: experience report \\ Promoción de la higiene de las manos: informe de la experiencia
}

Mayara Larissa de Almeida Santos

ORCID: https://orcid.org/0000-0003-0375-8418

Centro Universitário Mario Pontes Jucá, Brasil

E-mail: mayara.laryssa@hotmail.com

Jessyca Mayara de Araújo Lins Lima

ORCID: https://orcid.org/0000-0003-1111-4225

Centro Universitário Mario Pontes Jucá, Brasil

E-mail: jessyca.lima095@academico.fat-al.edu.br

Thaynara Carla Pontes de Almeida

ORCID: https://orcid.org/0000-0002-1130-4224

Centro Universitário Mario Pontes Jucá, Brasil

E-mail: thay_csu@hotmail.com

Gabriel Ferreira Lopes

ORCID: https://orcid.org/0000-0002-1724-3880

Centro Universitário Mario Pontes Jucá, Brasil E-mail: gabrielf.lopes12@gmail.com

Ewellyn Monique Silva Gomes Amâncio

ORCID: https://orcid.org/0000-0002-6380-5354

Centro Universitário Mario Pontes Jucá, Brasil

E-mail: ewellyn_amancio@ @otmail.com

Geraedson Aristides da Silva

ORCID: https://orcid.org/0000-0002-0057-3429

Centro Universitário Mario Pontes Jucá, Brasil E-mail: geraedson@hotmail.com

Clistenis Clênio Cavalcante dos Santos ORCID: https://orcid.org/0000-0002-9086-5782

Centro Universitário Mario Pontes Jucá, Brasil

E-mail: clistenis-cavalcante@ hotmail.com

Mariana Lima Albuquerque Jobim

ORCID: https://orcid.org/0000-0003-2175-3223

Centro Universitário Mario Pontes Jucá, Brasil

E-mail: marianalimaalbuquerque@gmail.com

Raquel Ferreira Lopes

ORCID: https://orcid.org/0000-0002-2061-7038

Centro Universitário Mario Pontes Jucá, Brasil

E-mail: raquelloppes@gmail.com

\begin{abstract}
Resumo
Objetivo: relatar a experiência de uma oficina sobre higienização das mãos com os profissionais de saúde de uma unidade hospitalar. Metodologia: trata-se de um estudo descritivo, do tipo relato de experiência. Resultados: A dinâmica evidenciou, não somente a importância do ato de higienizar as mãos, como também a importância dos recursos materiais disponíveis, a forma correta de utilizá-los e a estrutura física para que essa prática seja efetiva, além de oportunizar a disponibilização da sinalização das áreas da unidade hospitalar mostrando o passo a passo da higienização, motivo inicial do tema escolhido para esta ação devido à observação de sua ausência no início do estágio e fornecendo panfletos com os momentos para a higiene das mãos. Conclusão: Nessa perspectiva ficou irrefutável que para a construção de um fazer que priorize a constituição do compromisso dos profissionais de saúde para que os resultados sejam maximizados em prol da excelência nos serviços prestados a população, faz-se necessário promover mudanças de atitude e de trabalho de forma interdisciplinar e intersetorial, a fim de buscar melhores resultados na higienização das mãos.
\end{abstract}

Palavras-chave: Desinfecção das mãos; Equipe de assistência ao paciente; Infecção hospitalar.

\begin{abstract}
Objective: to report the experience of a workshop on hand hygiene with health professionals from a hospital unit. Metodologia: trata-se de um estudo descritivo, do tipo relato de experiência. Results: The dynamics highlighted not only the importance of hand hygiene, but also the importance of the material resources available, the correct way to use them and the physical structure for this practice to be effective, in addition to providing the opportunity to provide
\end{abstract}


signage of the areas of the hospital unit showing the step by step of hygiene, initial reason for the theme chosen for this action due to the observation of its absence at the beginning of the internship and providing pamphlets with the moments for hand hygiene. Conclusion: From this perspective, it was irrefutable that, in order to build a practice that prioritizes the constitution of the commitment of health professionals so that results are maximized for the sake of excellence in the services provided to the population, it is necessary to promote changes in attitude and work in an interdisciplinary and intersectoral way, in order to seek better results in hand hygiene.

Keywords: Hand disinfection; Patient care team; Cross infection.

\section{Resumen}

Objetivo: relatar la experiencia de una oficina sobre higiene de las manos con los profesionales de la salud de una unidad hospitalaria. Metodología: se trata de un estudio descriptivo, del tipo relato de experiencia. Resultados: La dinámica evidenció, no sólo la importancia del hecho de higienizar las manos, sino también la importancia de los recursos materiales disponibles, la forma correcta de usarlos y la estructura física para que esta práctica sea efectiva, además de posibilitar la sinalización de las áreas de la unidad hospitalaria mostrando el paso a paso de la higienización, motivo inicial del tema escogido para esta acción debido a la observación de su ausencia en el inicio de la estancia y el ofrecimiento de panfletos con los momentos para la higiene de las manos. Conclusión: Desde este punto de vista, es irrefutable que para la construcción de un negocio que priorice la constitución del compromiso de los profesionales de la salud para que los resultados se maximicen en el incremento de la excelencia en los servicios prestados a la población, es necesario promover cambios de actitud y de trabajo de forma interdisciplinar e intersetorial, con el fin de buscar mejores resultados en la higienización de las personas.

Palabras clave: Desinfección de las manos; Grupo de atención al paciente; Infección hospitalaria.

\section{Introdução}

Esta pesquisa tem como objeto de estudo a higienização das mãos como estratégia para a redução da incidência de infecções hospitalares, onde sua motivação se deu a partir de discussões teóricas e práticas durante os períodos letivos da formação profissional e que ganhou força no desenvolvimento do estágio hospitalar devido à constatação de sua importância e de que embora essencial foi observado que muitos profissionais veem como algo do qual não merece atenção ou por estarem tão atarefados esquecem da devida importância para essa prática tão vital pra vida de todos, inclusive para as dos próprios prestadores de serviços.

A higienização das mãos é a medida individual mais simples e menos dispendiosa para prevenir a propagação das infecções relacionadas à assistência à saúde. Atualmente, o termo lavagem das mãos foi modificado por higienização das mãos por conta da maior abrangência deste procedimento. O vocábulo abarca a higienização simples, a higienização antisséptica, fricção antisséptica e a antissepsia cirúrgica das mãos. Agência Nacional de Vigilância Sanitária [ANVISA] (2009).

A incidência de pacientes que desenvolvem infecções durante o contato direto dos profissionais nos cuidados de saúde vêm aumentando, calcula-se que, a cada dia, mais de 1,4 milhões de pessoas no mundo são diagnosticadas com infecções evitáveis relacionadas à assistência à saúde e, no Brasil, cerca de 3\% a 15\% das pessoas que estão hospitalizadas apresentam alguma infecção relacionada a assistência à saúde, que pode agravar a saúde do paciente, prolongar a permanência hospitalar, elevar os custos do tratamento e levar ao óbito. As tendências atuais, a consciência pública e o aumento dos custos dos cuidados de saúde têm aumentado a importância da prevenção e controle das infecções que são essenciais para criar um ambiente de cuidados de saúde seguro para clientes, familiares e funcionários, onde as enfermeiras exercem um papel primordial na prevenção e controle dessas infecções (Souza et al., 2015).

Os pacientes estão sujeitos a adquirir infecções em todos os ambientes de prestação de cuidados de saúde, devido a inúmeras causas aos quais venham a ser submetidos. Consoante a devida magnitude do polêmico assunto para a segurança do paciente, indica-se com isso a necessidade de práticas básicas de prevenção e controle de infecções evitando a disseminação de patógenos para os pacientes, familiares e funcionários da unidade de saúde (Anacleto et al., 2013).

No Brasil, observa-se empenho face ao combate de contaminação, onde na legislação brasileira por meio da RDC 50/2002, se define as condutas mínimas a serem concebidas com intuito de redução da incidência das infecções relacionadas à assistência à saúde. A organização mundial de saúde (OMS), por meio da aliança mundial para a segurança do paciente, 
também tem desvelado esforços na elaboração de orientação e métodos de inserção de disposições visando à adesão a prática de higiene das mãos (Silva et al., 2018).

O estudo se justifica por ser um tema estratégico dentro das unidades de saúde e por promover a conscientização da importância da higienização das mãos corretamente, em todos os momentos preconizados por todos os profissionais envolvidos no cuidado, desde colaboradores administrativos aos profissionais que prestam cuidados diretos aos pacientes.

A importância desse trabalho se dá na perspectiva dos profissionais de saúde estarem em posição essencial para a prevenção e controle de infecções tomando por base a higienização das mãos como medida individual para prevenir a propagação das infecções relacionadas à assistência à saúde, e como membros da equipe de saúde com a responsabilidade profissional de se engajar em atividades que dão suporte à cultura de segurança centrada no paciente sugerindo assim uma educação continuada dessa medida que é a mais simples e menos dispendiosa porém de suma importância para a segurança de todos.

Dessa forma o presente estudo teve como objetivo relatar a experiência de uma oficina sobre higienização das mãos com os profissionais de saúde de uma unidade hospitalar.

\section{Metodologia}

Este estudo trata-se de um estudo descritivo, do tipo relato de experiência, que traz uma apresentação de uma reflexão sucinta, a partir de uma organização estruturada pelo próprio formador, indicando os aspectos positivos e as dificuldades identificadas na organização e no desenvolvimento de sua experiência, os resultados e outros elementos que julgar pertinentes. Contendo de forma geral, informações sobre o que foi realizado, conforme planejamento, e os resultados alcançados fazendo a relação entre a teoria e a prática, conhecimentos desenvolvidos no curso e aplicados na prática trazendo contribuições para o ensino a partir da vivência prática (Universidade Federal De Juiz De Fora, 2017; Cortes et al., 2018).

Vivenciado a partir do estágio supervisionado hospitalar, no Hospital Santa Casa de Misericórdia, localizado no município de São Miguel dos Campos - Alagoas, entidade filantrópica e que integra a quinta região de saúde do Estado de Alagoas. Cabe ressaltar que não houve necessidade de submissão ao Comitê de Ética em Pesquisa, por se tratar de um relato de experiência.

Para a construção deste estudo foram realizadas observações no dia a dia pelos estudantes no hospital Santa Casa de Misericórdia de são Miguel dos Campos em Alagoas quanto aos hábitos de higienização das mãos, sinalização dos ambientes do hospital, análise de variáveis importantes ao desenvolvimento do cuidado dispensado aos indivíduos ou aos seus problemas voltados para a temática do estudo abordado, um planejamento com as ações a serem realizadas, estratégias de soluções, resultados esperados e o prazo desse plano de ação.

A proposta da atividade educativa era criar uma caixa com o intuito de simular a higienização das mãos de modo a observar como os profissionais de saúde do local da experiência estavam realizando o mesmo, orientando assim a forma correta, a duração correta e as oportunidades preconizadas pelo Ministério da Saúde e pela ANVISA. A ideia inicial surgiu a partir da preceptora de estágio que já havia escutado sobre trabalhos realizados com simulação através de uma caixa reveladora de bactérias.

Após embasamento teórico sobre modelos de simulação foi construído uma caixa de simulação de madeira com área de $1.720 \mathrm{~cm}^{2}$, devido seu material mais resistente e com alta durabilidade para sustentar um tampo de vidro fumê na parte superior central que permite a visualização das mãos, além de comportar melhor o bocal com a luz negra na parede lateral direita e o forro em tecido não tecido (TNT) preto cobrindo todo o interior da caixa de forma a mantê-la escura o suficiente para permitir uma melhor visualização das regiões das mãos as quais não foram bem higienizadas (Gonçalves \& Bospin, 2018). Ilustrado na Figura 1. 
Figura 1 - Frente da caixa de simulação realística.

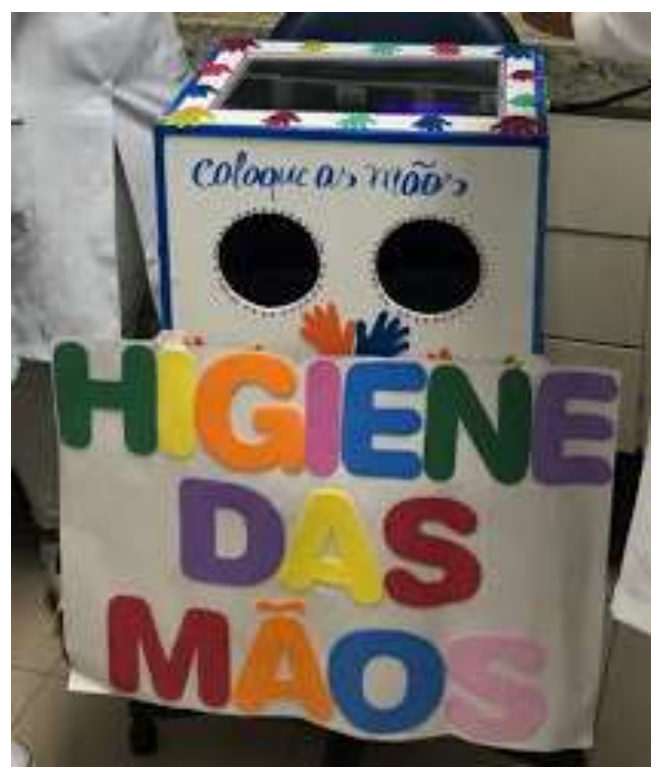

Fonte: Autores (2021).

Para possibilitar a entrada das mãos na caixa foram feitas duas aberturas em formato de círculo na parte frontal da mesma cor para proporcionar a realização da simulação das mãos no interior da caixa sem que os profissionais pudessem encostar suas mãos na luz negra. Na parte externa foi realizada pintura manual com tinta guache de cores diversas, com a reprodução das mãos das estagiárias, colagem com tecido e emborrachado coloridos também com ilustração de mãos, fita colorida e adesivo do tipo strass, na lateral da caixa foi colado papel couche adesivo de tamanho A3 com o passo a passo da higienização das mãos preconizados pela ANVISA, ilustrados nas Figuras 2 e 3.

Figura 2 - Decoração da parte lateral da caixa ilustrando molde das mãos.

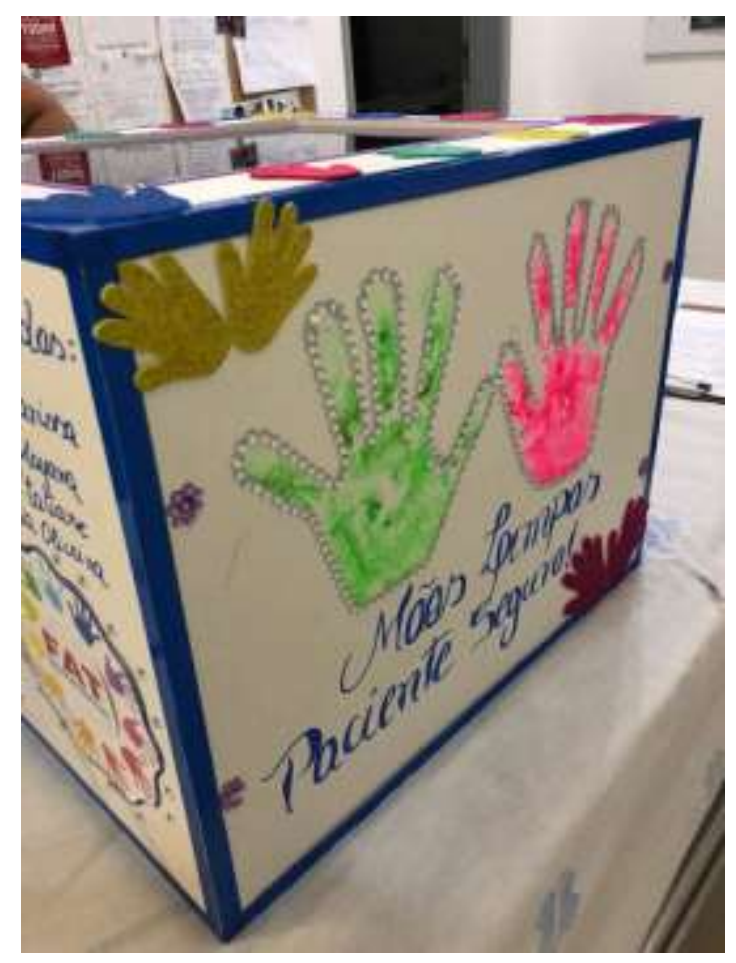

Fonte: Autores (2021). 
Figura 3 - Passo a passo da higienização das mãos em uma das laterais da caixa.

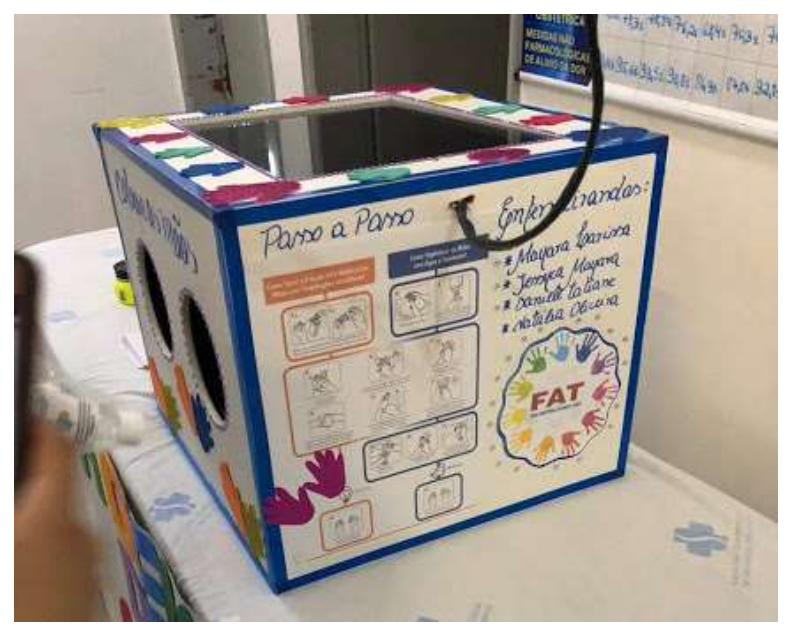

Fonte: Autores (2021).

O vidro colocado na porção superior teve como intenção não só a visualização das mãos como também para intensificar a luz negra. Utilizando-se gel de cabelo neon para a demonstração das partes friccionadas de forma inadequada, ilustrado na Figura 4.

Logo após, foi disponibilizado o gel neon de cabelo aos profissionais presentes nos setores da clínica médica, urgência e emergência, alojamento conjunto, pavilhão, centro cirúrgico, maternidade, unidade de terapia intensiva, UTI neonatal e UCI solicitando que os mesmos realizassem a técnica de higienização das mãos conforme prática diária e, em seguida inserissem suas mãos na caixa para a verificação da eficácia da higienização e de fricção. O gel neon de cabelo serviu como o luminol destacando as regiões onde a fricção foi efetiva, bem como nas regiões mais escurecidas mostrou a fricção não efetiva pela falta do gel ou tempo de fricção.

A dinâmica teve a participação de todos os colaboradores presentes nos dois dias da realização da atividade conforme suas escalas de trabalho, alcançando todas as unidades da instituição, assim possuindo um caráter multidisciplinar, caracterizado por uma metodologia ativa de ensino. Este momento serviu como uma oportunidade para incentivar uma reflexão acerca da responsabilidade de todos os profissionais da unidade que estejam no cuidado direto e indireto de pacientes, além de esclarecer a dúvidas que porventura surgiram e até mesmo para dispor de novas informações. 
Figura 4 - Posicionamento das mãos dos profissionais de saúde dentro da caixa.

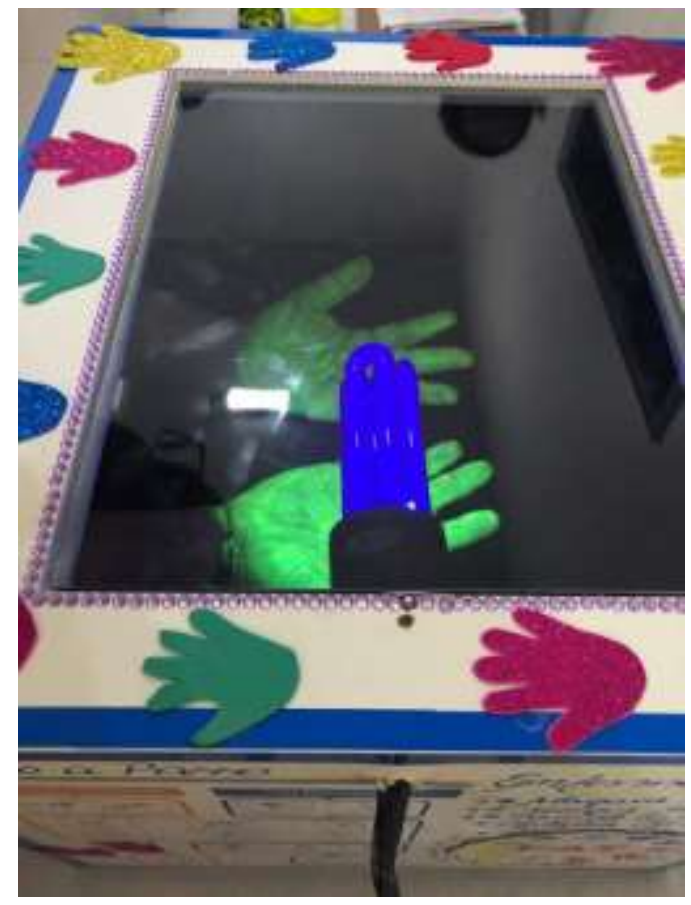

Fonte: Autores (2021).

Figura 5 - Pontos escuros de falha da técnica de higienização realizada.

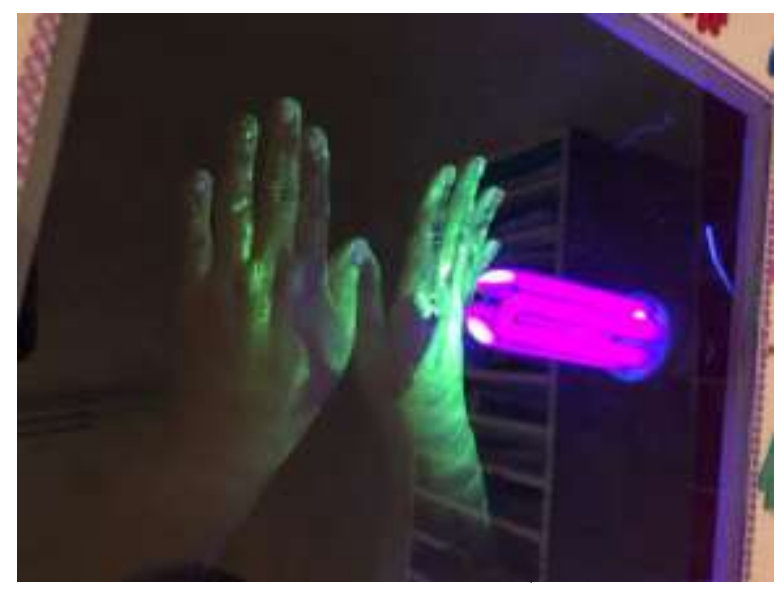

Fonte: Autores (2021).

\section{Resultados e Discussão}

A ação realizada durante o estágio possibilitou as enfermeirandas à interação e a troca de experiências com os profissionais dos diversos setores onde foi realizado a simulação, ficando evidente a importância de uma adequada higienização das mãos em todas as oportunidades da assistência à saúde garantindo assim menor risco de contaminação para todos os envolvidos, além de permitir a observação da magnitude da educação continua evitando assim vícios da profissão.

Notou-se que essa troca de experiências e saberes proporcionou uma aproximação maior possibilitando o desenvolvimento dos processos de aprendizagem a partir das práticas cotidianas, especialmente pelo fato de propiciar o confronto da teoria com o dia a dia da profissão, as necessidades e desejos da sociedade. Além disso, a proposta da atividade ensejou a interação entre as diversas áreas do hospital a fim de atingir um objetivo comum, permitindo a comunicação e 
diálogo com outras formas de conhecimento a fim de construir e solidificar uma reflexão acerca da seriedade das práticas de higienização das mãos conforme preconizado para uma assistência de qualidade, com menor custo e proteção para pacientes, familiares e profissionais de saúde.

O processo de educação em saúde precisa ser notado como essencial para a prevenção, tendo como objetivo o cuidado de vida e melhoria da população. Para tanto se faz necessário que seja realizada de forma organizada e declarada como fator preponderante pelos profissionais de saúde provocando uma reflexão e mudanças de comportamento na vida dos indivíduos, contribuindo dessa forma para que as pessoas possam conquistar autonomia para detectar e usufruir das condições e recursos para resguardar e melhorar sua vida (Oliveira \& Gonçalves, 2004).

Durante as atividades desenvolvidas nos setores, os profissionais ali presentes se mostraram ativos participando do momento de exposição das orientações sobre o tema proposto e também da simulação da técnica como preconizada pela Organização Mundial de Saúde (OMS) e pelo Ministério da Saúde (MS) participando desse momento de interação e inclusive indo em busca dos colegas de trabalho que não estavam presentes para participarem desse momento de treinamento de higiene das mãos.

A higienização das mãos pode ser feita esfregando as mãos com composição alcoólica ou higienizando com água e sabão, o que faz com que as mãos fiquem seguras de contaminação por microrganismos potencialmente prejudicial e também protegida para a assistência à saúde do paciente, tendo dessa forma a finalidade de remover sujidade, microbiota da pele, células descamativas, etc. com o intuito de impedir infecções relacionadas ao contato. Antes de iniciar qualquer umas das técnicas de higienização das mãos deve-se retirar todos os adereços utilizados e estar ciente de que a eficácia da higienização depende do tempo e do passo a passo recomendado, onde essa duração vai variar segundo a técnica utilizada, como por exemplo, a higienização simples das mãos que tem a durabilidade de 40 a 60 segundos; higienização alcoólica de 20 a 30 segundos e antissepsia cirúrgica com duração de 3 a 5 minutos para a primeira cirurgia e de 2 a 3 minutos para a cirurgias subsequentes (ANVISA, 2009).

As infecções relacionadas à assistência à saúde (IRAS) representam um problema sério e têm um impacto econômico significativo nos pacientes e sistemas de saúde do mundo todo. No entanto, a correta higienização das mãos que é considerada uma ação simples pode salvar vidas se realizadas no momento certo e da maneira certa. Porém, embora essa seja considerada a medida mais importante e reconhecida há muitos anos na prevenção e controle das infecções nos serviços de saúde, colocá-la em prática consiste em uma tarefa complexa e difícil (ANVISA, 2009).

Tal fato foi constatado no dia a dia das enfermeirandas onde se verificou que a adesão à prática de higienização das mãos de forma constante e na rotina diária é insuficiente por diversos fatores, como por exemplo, os observados e inclusive citados pelos próprios profissionais como a quantidade de procedimentos e o pouco tempo, a falta de materiais para a higienização, dentre outros.

Vale ressaltar que abordar a higiene das mãos focando em apenas cinco indicações, tem por objetivo o de facilitar o entendimento dos momentos em que existe risco de transmissão de microrganismos pelas mãos, memorizá-los e incorporá-los nas atividades assistenciais, sendo utilizados como abordagem de referência para a prática correta, o ensino e a avaliação da higienização das mãos, cabendo desse modo salientar que existe uma longa lista de ações e situações assistenciais que exigem a higiene das mãos (Ribeiro et al., 2017).

No ato da simulação da higienização das mãos, primeiramente foi realizado um momento onde foi fornecido informações sobre a importância da sua adesão para a prevenção de infecções, deixando claro que as mãos estão envolvidas em todo o processo de atendimento tornando-se o principal veículo de transmissão de micro-organismos, além da existência de sua microbiota transitória e residente; que a importância da prevenção através da higiene das mãos é uma forma custo efetiva para reduzir as infecções relacionadas à assistência à saúde, evitando causar sofrimento físico e moral para os pacientes e seus 
familiares.

Com a visualização de suas próprias mãos, houve a observação e esclarecimentos sobre a importância da quantidade de vezes do uso de preparação alcoólica ou água e sabão, tempo de fricção, quantidade suficiente para cobrir a palma das mãos, fazendo com que suas práticas de higienização das mãos fossem postas à prova e, fazendo-os perceber que o cuidado em saúde precisa ser conduzido com consciência, responsabilidade profissional e compromisso assumido com o outro, no zelo de sua saúde e segurança, livre de danos evitáveis, como determinam os códigos de ética das profissões da área da saúde.

Salienta-se que perceberam que assistência à saúde não se faz apenas com conhecimento mais também com a realização da técnica correta e em todas as oportunidades de aderência a essa prática com a certeza e concepção de que é imprescindível para a segurança do paciente, definida como a redução, a um mínimo aceitável, do risco de danos desnecessários à atenção à saúde.

Ainda que os profissionais da área da saúde possuam compreensão dos momentos em que a higienização das mãos deve acontecer e de sua relevância, percebeu-se uma resistência e uma diminuição na frequência dos procedimentos necessários para essa prática que pode ser ressaltada através dos relatos sobre os aspectos que dificultam a técnica estabelecida. Achados que corroboram com outros estudos em que apontam como fatores dificultadores para adesão da higienização das mãos: a pressa, falta de tempo, esquecimento, distância da pia, falta de equipamentos e materiais necessários, falta de exemplo de outros profissionais, ressecamento da pele, falta de pessoal, má distribuição dos dispensadores e alergia ao produto disponível, necessitando dessa forma ampliação e realização de ações educativas para a conscientização e reciclagem dos profissionais (Magnago et al., 2019).

Como resultado desta ação conjunta, destaca-se o déficit no processo de higienização das mãos na região entre as falanges, principalmente nos polegares e nas laterais dos dedos mínimos, e em alguns casos nas regiões dos dorsos das mãos. De forma geral todos os profissionais que participaram da simulação foram bem-sucedidos nos processos de higienização das mãos (Silva et al., 2016).

A dinâmica evidenciou, não somente a importância do ato de higienizar as mãos, como também a importância dos recursos materiais disponíveis, a forma correta de utilizá-los e a estrutura física para que essa prática seja efetiva, além de oportunizar a disponibilização da sinalização das áreas da unidade hospitalar mostrando o passo a passo da higienização, motivo inicial do tema escolhido para esta ação devido à observação de sua ausência no início do estágio e fornecendo panfletos com os momentos para a higiene das mãos.

Existem baixas taxas de adesão a higienização das mãos por falta de materiais ou materiais insuficientes para a realização da prática preconizada de forma adequada, como por exemplo falta de álcool-gel, sabonete neutro, papel toalha e falta de infraestrutura necessária para a garantia de um atendimento eficaz e de qualidade sem risco de transmissão de microrganismo para o paciente (Llapa-Rodriguez et al., 2018).

O uso dessa simulação realística foi uma estratégia inovadora utilizada no plano de ação que servirá para a realização de treinamentos e educação continuada na unidade hospitalar já que a caixa foi doada para a instituição e que pode servir de ideia inovadora para outras instituições de saúde assim como de ensino e cursos de capacitação por reproduzir experiências do cotidiano fomentando um ambiente de interações entre os participantes, facilitando o processo de ensino-aprendizagem dos profissionais acerca da prevenção de infecções hospitalares e demonstrando na prática que por mais conhecimento que se tenha sobre as técnicas é de suma importância que mesmo diante das dificuldades da rotina de trabalho é necessário que todos os profissionais envolvidos na assistência seja, de forma direta ou indireta, se policie quanto a essa prática simples e eficiente, com objetivo de promover o controle de infecções, aumentar a qualidade no cuidado, otimizar custos, reduzir a morbimortalidade, porém que ainda possui adesão insuficiente nas unidades de saúde. 


\section{Conclusão}

Esse trabalho foi de suma importância, pois permitiu a percepção da higienização das mãos como fator primordial para o controle das infecções relacionadas à assistência à saúde, uma vez que as mãos caracterizam-se como principal ferramenta de transmissão dos microorganismos; os desafios enfrentados para a implantação de estratégias, para a promoção da higienização das mãos; e a importância do desenvolvimento de conhecimento sobre o assunto a fim de valorizar a segurança e a qualidade da assistência.

É ímpar a relevância do papel dos profissionais de saúde no cuidado com o indivíduo e deve estar em constante interação como o processo de campanhas e treinamentos permanentes de higiene das mãos, visando dessa forma nortear suas ações para melhor atender aos pacientes e proporcionar ações de mudanças no cenário da assistência.

Os profissionais da saúde participantes da simulação da higiene das mãos nos dois dias do plano de ação se mostraram motivados e abertos a dinâmica proposta pelos estudantes, estando presentes tanto no momento das informações sobre a importância da higienização das mãos e relatando seus conhecimentos, como no momento da simulação da sua técnica diária com bastante entusiasmo e desempenho.

Nessa perspectiva ficou irrefutável que para a construção de um fazer que priorize a constituição do compromisso dos profissionais de saúde para que os resultados sejam maximizados em prol da excelência nos serviços prestados a população, faz-se necessário promover mudanças de atitude e de trabalho de forma interdisciplinar e intersetorial, a fim de buscar melhores resultados na higienização das mãos.

Este estudo possibilitou refletir sobre a necessidade de atualizações, como meio de possibilitar um maior debate sobre o tema, abordando a realização da técnica correta de higienização das mãos, com o objetivo de tirar dúvidas, além de estimular a conscientização da equipe em face de a segurança do ambiente, do paciente e do próprio profissional no seu cotidiano hospitalar. Isso porque somente o conhecimento sobre infecção hospitalar e suas medidas preventivas, não garante adesão e eficácia da higienização das mãos.

Ficou evidenciado que para se obter sucesso e que esse conhecimento leve a resultados como o aumento da taxa de adesão a higienização das mãos e a sua manutenção; a realização da maneira correta e em todas as oportunidades que vão além dos cinco momentos preconizados, deve-se em primeiro lugar determinar o envolvimento desses profissionais, oportunizando seu devido aperfeiçoamento e impulsionando sua motivação, nas distintas áreas de atendimento aos pacientes, se tornando métodos chaves na redução dos indícios de infecções hospitalares e na implantação de práticas corretas e seguras, além de melhorias da infraestrutura e de disponibilização de recursos para essa prática tão importante e que pode salvar vidas.

Por fim, observou-se que, apesar do conhecimento obtido no decorrer do tempo e a comoção pelas campanhas realizadas, a adesão á prática de higienização das mãos pelos profissionais de saúde está longe das diretrizes nacionais e internacionais, principalmente frente ao contexto atual, com o aumento de infecções por microrganismos multirresistentes, o que é um risco à segurança dos pacientes. Sugere-se como pesquisas futuras, trabalhos de intervenções realizados com os profissionais de saúde das unidades hospitalares sobre a correta higienização das mãos, a fim de melhorar a adesão e qualificação dos profissionais.

\section{Referências}

Alves, F. C. (2017). A Higienização das Mãos: Um Olhar Sobre Edificação do Treinamento no Processo de cuidar. Relatório de Pesquisa para Pós-Graduação em Saúde e Tecnologia no Espaço Hospitalar.

Anacleto-Belela, C. S. A., Peterlini, S. A. M., \& Pedreira, G. L. M. (2017) Higienização das Mãos como Prática do Cuidar: Reflexão Acerca da Responsabilidade Profissional. Revista Brasileira de Enfermagem, 70(2), 461 - 464 https://www.scielo.br/pdf/reben/v70n2/pt_0034-7167-reben-70-020442.pdf. 
Anacleto-Belela, C. S. A., Sousa, C. E B., Yoshikawa, M. J., Avelar, M. F. A., \& Pedreira, G. L. M. (2013) Higienização das Mãos e a Segurança do Paciente: Perspectiva de Docentes e Universitários. Revista Texto Contexto de Enfermagem, 22(4), 901 - 908. https://www.scielo.br/pdf/tce/v22n4/05.pdf.

Bathke, J., Cunico, A. P., Maziero, S. c. E., Cauduro, F. L. F., sarquis, M. M. L., \& Cruz, A. D. E. (2013) Infraestrutura e Adesão à Higienização das Mãos: Desafios à Segurança do Paciente. Rev. Gaúcha de Enfermagem, 34(2), 78 - 85https://www.scielo.br/scielo.php?script=sci_arttext\&pid=S198314472013000200010

Calil, K., Cavalcanti, V. G. S., \& Silvino, Z. R. (2014) Ações e/ou Intervenções de Enfermagem para Prevenção de Infecções Hospitalares em Pacientes Gravemente Enfermos: uma Revisão Integrativa. Enfermagem Global, 13(34), 425 - 443. http://scielo.isciii.es/pdf/eg/v13n34/pt_revision4.pdf.

Coelho, M.S., Silva, A. C., \& Faria, S. S. M. (2011) Higienização das Mãos como Estratégia Fundamental no Controle de Infecção Hospitalar: Um Estudo Quantitativo. Rev. Enfermagem Global, 10 (21), 02-12. http://scielo.isciii.es/pdf/eg/v10n21/pt_clinica2.pdf.

Cortes, L. F., Padoin, S. M. M. \& Berbel, N. A. N. (2018). Problematization Methodology and Convergent Healthcare Research: praxis proposal in research. Rev Bras Enferm. 71(2):440-5. doi: http://dx.doi.org/10.1590/0034-7167-2016-0362

Derhun, M. F., Souza, S. V., Costa, R. A. M., Hayakawa, Y. L., Inoue, C. K., \& Matsuda, M. L. (2018) Uso da Preparação Alcoólica Para Higienização das Mãos. Rev. De Enfermagem,12(2), 320 - 328.

Filho, Q. S. A., Henriquess, P. M. C., Silva, A. A. J., \& Britto, M. C. M. Segurança do Paciente: Higiene das Mãos. Agência de Vigilância Sanitária. (n. d).

Flores-Anaya, E. V; Cazares-Conde, N., Garcia-Castillho, L., Moreno-Léon, C., Simpson, A. B. (2009) Conhecimento da Equipe de Enfermagem Sobre Infecções Nosocomiais, Prevenção e Prática das Medidas de Segurança e Higiene. Rev. De Enfermagem Inst. Mex., 17(3), 133-138.

Gonçalves, B., \& Bopsin, P. (2018). Promoção da higienização das mãos através de técnicas lúdico-educativas em um hospital público. Caminho AbertoRevista de Extensão do IFSC, 5(9), 77-80.

Korb, P. J; Jerzewski, G., Aozane, F., Feldhaus, C., Kolankiewicz, B. C. A., \& Loro, M. M. (2019) Conhecimento Sobre Higienização das Mãos na Perspectiva de Profissionais de Enfermagem em um Pronto Atendimento. Rev. Online de Pesquisa, 11, 517 - 523.

Magnago, T. S. B. D. S., Ongaro, J. D., Greco, P. B. T., Lanes, T. C., Zottele, C., Gonçalves, N. G., \& Andolhe, R. (2019). Infraestrutura para higienização das mãos em um hospital universitário. Revista Gaúcha de Enfermagem, 40.

Medeiros, C. K., Azevedo, C. I., Cruz, P. K. G., Carvalho, P. R. S. P. D., Botarelli, R. F., \& Júnior, F. A. M. (2019) Higienização das Mãos Entre Profissionais de Enfermagem Circulantes de Sala Operatória. Rev. Enfermagem Atual, Natal, 81(19), 63 - 69. https://revistaenfermagematual.com/inde x.php/revista/article/view/322/207.

Oliveira, C. A., Paula, O. A., \& Gama, S. C. (2017) Monitorização da higiene das mãos: Observação Direta Versus Taxa Autorreportada. Rev. Enfermagem Global, 16 (48), 334 - 343. https://digitum.um.es/digitum/bitstream/10201/54417/1/277861-1044261-1-PB.pdf.

Oliveira, G. R. (2016) Blackbook Enfermagem. Blackbook.

Oliveira, C. A., \& Paula, O. A. (2013) Intervenções para Elevar a Adesão dos Profissionais de Saúde à Higiene das Mãos: Revisão Integrativa. Revista Eletrônica de Enfermagem, 15(4). https://www.fen.ufg.br/fen_revista/v15/n4/pdf/v15n4a24.pdf.

Oliveira, H. M. D., \& Gonçalves, M. J. F. (2004). Educação em saúde: uma experiência transformadora. Revista Brasileira de Enfermagem, 57,761 -763.

Ribeiro, F. D. D. O., Souza, M. A. D., Paula, A. O. D., Silva, A. G. D., \& Oliveira, A. C. D. (2017). Estratégia lúdica para a melhoria de práticas de higienização das mãos entre os profissionais de saúde. Rev. enferm. UFPE on line, 3971-3979.

Rodiguez, L. O. E., Oliveira, A. K. J., Menezes, O. M., Silva, L. S. L., Almeida, M. D., Neto, L. D. (2018) Aderência de Profissionais de Saúde à Higienização das Mãos. Rev. De Enfermagem, 12(6), 1578 - 1585.

Santos, R. C. T., Roseira, E. C., Morais-Piai, H. T., \& Figueiredo, M. R. (2014) Higienização das Mãos em Ambiente Hospitalar: Uso de Indicadores de Conformidade. Rev. Gaúcha de Enfermagem, 35(1), 70-77. https://www.scielo.br/pdf/rgenf/v35n1/pt_1983-1447-rgenf-35-01-00070.pdf.

Saúde, M. O. (n. d). Manual de Referência Técnica para a Higiene das Mãos: para Ser Utilizado por Profissionais de Saúde, Formadores e observadores de Prática de Higiene das Mãos. Geneva, 01-35.

Silva, R. B., Carreiro, A. M., Simões, T. F. B., \& Paula, G. D. (2018) Monitoramento da Adesão à Higiene das Mãos em Uma Unidade de Terapia Intensiva. Rev. Enfermagem, 26(4), 01 - 05. https://www.e-publicacoes.uerj.br/index.php/enfermagemuerj/article/view/33087.

Silva, M. D., Marques, M. B., Galhardi, M. N., Orlandi, S. F., \& Figueiredo, M. R. (2017) Higiene das Mãos e Uso de Luvas Pela Enfermagem em Hemodiálise. Rev. Brasileira de Enfermagem, v. 71(4), 2078-2084. https://www.scielo.br/pdf/reben/v71n4/pt_0034-7167-reben-71-04-1963.pdf.

Silva, S. M., Tourinho, F. S. V., Gurgel, P. K. F., Fernandes, L. G. G., de Medeiros, K. S., \& Santos, V. E. P. (2016). Higienização das mãos para a segurança do paciente: análise de imagens do site Google. Revista Brasileira de Inovação Tecnológica em Saúde-ISSN: 2236-1103.

Silva, M. F., Porto, P. T., Rocha, K. P., Lessman, C. J., Cabral, A. F. P., \& Schneider,K. L. K. (2013) Higienização das Mãos e a Segurança do Paciente Pediátrico. Rev. Ciência e Enfermagem, 19(2), 99 - 109. https://scielo.conicyt.cl/pdf/cienf/v19n2/art_10.pdf.

Souza, S. H. V. (2015) Hospital: Manual de Ambiente Hospitalar. Curitiba: Divulgação Cultura.

Souza, M. L., Ramos, F. M., Becker, S. S. E., Meirelles, S. C. L., \& Monteiro, O. A. S. (2015) Adesão dos Profissionais de Terapia Intensiva aos Cindo Momentos da Higienização das Mãos. Rev. Gaúcha de Enfermagem, 36(4), 21-28. https://www..scielo.br/rgenf. 
Research, Society and Development, v. 10, n. 16, e347101623842, 2021

(CC BY 4.0) | ISSN 2525-3409 | DOI: http://dx.doi.org/10.33448/rsd-v10i16.23842

Trannin, P. P. K., Campanharo, V. R. C., Lopes, T. B. C. M., Okuno, P. F. M., \& Batista, A. E. R. (2016) Adesão à Higiene das Mãos: Intervenção e Avaliação. Cogitare Enfermagem, 21(2), 01 - 07. http://ojs.c3sl.ufpr.br/ojs2/index.php/cogitare/.

Universidade Federal de Juiz de Fora. (2017). Instrutivo para Elaboração de relato de Experiência. https://www.uff.br/nutricaogv/files/2016/03/Orienta\%C3\%A7\%C3\%B5esElabora\%C3\%A7\%C3\%A3o-de-Relato-de-Experi\%C3\%AAncia.pdf.

Valim, D. M., Rocha, S. L. I., Souza, M. P. T., Cruz, A. Y., Bezerra, B. T., Baggio, E. Morais, B. R., \& Ribeiro, C. A. (2018) Eficácia da Estratégia Multimodal para à Higiene das Mãos: Revisão Integrativa. Rev. Brasileira de Enfermagem, 72(2), 578-592. https://www.scielo.br/pdf/reben/v72n2/pt_00347167-reben-72-02-0552.pdf.

Vasconcelos, O. R., Alves, I. C. D., fernandes, M. L., \& Oliveira, C. L. J. (2018) Adesão à Higiene das Mãos pela Equipe de Enfermagem em Unidade de Terapia Intensiva. Enfermagem Global, 17(50), 446-461. http://scielo.isciii.es/pdf/eg/v17n50/pt_1695-6141-eg-17-50-430.pdf.

Zottele, C., Magnago, T. S. B. S., Dullius, A. I. S., Kolankiewicz, A. C. B., \& Ongaro, J. D. (2017) Adesão dos Profissionais de Saúde à Higienização das Mãos em Pronto Socorro. Revista Da Escola de Enfermagem, 51, 01 - 07 https://www.scielo.br/pdf/reeusp/v51/pt_1980-220X-reeusp-51-e03242.pdf. 